\title{
PESSOAS COM DEFICIÊNCIA E PSICANÁLISE: INTERSECÇÃO PELA EDUCAÇÃO INCLUSIVA DE QUALIDADE
}

\author{
Rogério Luiz Nery da Silva ${ }^{1}$ \\ Darléa Carine Palma Mattiello ${ }^{2}$
}

Resumo: O estudo adota por tema a educação inclusiva e recorta, como justificativa, os óbices à categorização das deficiências. Objetivo: verificar a existência de eventual nexo educação inclusiva - deficiências - psicanálise que autorize seu uso no diagnóstico. O problema de pesquisa questiona a compatibilidade do emprego da psicanálise como ferramenta de diagnóstico dessas deficiências. Como resultado, confirma-se viabilidade do uso da psicanálise no processo de reconhecimento dos impedimentos, incapacidades e deficiências aptos a inviabilizar a educação inclusiva. A metodologia adotada emprega a pesquisa bibliográfica e documental, com abordagem qualitativa e método hipotético-dedutivo.

Palavras-chave: Direito à educação; direito à inclusão; educação inclusiva; pessoas com deficiência; psicanálise.

\section{PEOPLE WITH DISABILITIES AND PSYCHOANALYSIS: AN INTERSECTION FOR QUALITY INCLUSIVE EDUCATION}

Abstract: This research issues inclusive education as theme and highlights obstacles to the disabilities categorization as its formal justification. Its main goal is verifying any nexus between inclusive education - disabilities - psychoanalysis which allows the use of psychoanalysis in disabilities diagnosis. The research problem questions possible compatibility for using psychoanalysis on diagnosing deficiencies. The expected result sustains the feasibility of psychoanalysis in the diagnosis, in the process of recognizing impediments, incapacities and deficiencies all able to unfease inclusion. The methodologic method is hypothetical-deductive, by qualitative approach with bibliographic and documental assessment.

Keywords: Right to education; right to inclusion; inclusive education; people with disabilities; psychoanalysis.

\section{INTRODUÇÃO}

Direito e inclusão são temas que se vinculam de longa data. As práticas inclusivistas e as matérias jurídicas possuem estreita relação porque, comumente, é por meio das previsões

\footnotetext{
${ }^{1}$ Pós-Doutor pela Université de Paris X (França) e pela New York Fordham University (USA). Doutor em Direito pela Universidade Estácio de Sá - Unesa. Posgrado en Justicia y Procesos Constitucionales pela Universidad Castilla-La Mancha (Espanha). Professor Programa Erasmus (União Europeia) na Cardinal Stefan Wyszynski University (Varsóvia - Polônia). Professor na Università degli Studi di Foggia (Itália). Professor no Programa de Pós-Graduação Stricto Sensu em Direito da Universidade do Oeste de Santa Catarina - Unoesc. Advogado. Endereço eletrônico: dr.nerydasilva@ gmail.com. ORCID: http://orcid.org/0000-0003-4317-5903.

${ }^{2}$ Doutoranda em Direito pela Universidade do Oeste de Santa Catarina - Unoesc.. Mestra em Direito pela Unoesc, com período sanduíche na Università degli Studi di Foggia (Itália). Pesquisadora vinculada ao Programa de Pós-Graduação Stricto Sensu em Direito da Unoesc. Professora na graduação e pós-graduação da Unoesc. Editora assistente da Revista Espaço Jurídico Journal of Law (CAPES Qualis A1). Advogada. Endereço eletrônico: darlea.palma@ unoesc.edu.br. ORCID: http://orcid.org/0000-0003-1342-4681.
} 
normativas que são efetivados os direitos das pessoas com deficiência, garantindo-lhes maior inserção no meio social e o exercício do que lhes é tutelado em lei em termos de inclusão.

A presente pesquisa possui como tema o direito à educação inclusiva e, como recorte, os óbices à sua efetivação, no cenário das políticas públicas veiculadas pelo Estado com vistas à inclusão escolar das pessoas que possuem alguma ou mais deficiências, em maior ou menor grau de severidade.

O problema de pesquisa consiste em identificar o possível vínculo da psicanálise com a prestação da educação inclusiva, no sentido de apontar eventuais contribuições dos estudos psicanalíticos para uma maior efetividade do direito à educação no Brasil. Nesse ponto, justifica-se o estudo e aponta-se sua relevância social, jurídica e acadêmica, uma vez que, apurada a inefetividade de políticas educacionais substancialmente inclusivas, devem ser perseguidas contribuições para uma maior concretização do direito à educação às pessoas com deficiência, o que pode ser feito, segundo a presente proposta, com o estudo da psicanálise.

O objetivo geral do estudo consiste em esclarecer o possível nexo existente entre pessoas com deficiência, a efetiva prestação educacional e psicanálise, a partir de uma análise multidisciplinar. Os objetivos específicos, por sua vez, são: elucidar os principais conceitos relacionados à educação enquanto direito fundamental, social e subjetivo, como objeto de prestação estatal que deve ser viabilizada com qualidade; estabelecer a definição contemporânea de pessoa com deficiência e sua categorização normativa; esboçar noções inicias de psicanálise, principalmente com base freudiana, identificando como o estudo psicanalítico pode contribuir no processo de identificação dos impedimentos aptos a configurarem deficiências e capazes de inviabilizar a educação inclusiva.

Em termos metodológicos, utiliza-se pesquisa bibliográfica e documental, com estudos doutrinários, normativos e índices levantados por fontes confiáveis de pesquisa, como o Instituto Brasileiro de Geografia e Estatística - IBGE e o Washington Group on Disability Statistics, vinculado à Divisão de Estatísticas do Departamento de Assuntos Econômicos e Sociais das Nações Unidas. A abordagem é qualitativa, com predominância do método hipotético-dedutivo.

A pesquisa está estruturada com as seguintes delimitações: a seção introdutória, o texto com desenvolvimento do tema principal, a conclusão e as referências bibliográficas. A parte em que se discorre sobre a intersecção havida entre pessoas com deficiência e psicanálise na busca pela educação inclusiva de qualidade encontra-se na segunda e na 
terceira seções do artigo, nas quais são abordados os conceitos relacionados a educação, inclusão das pessoas com deficiência e efetividade prestacional, bem como o nexo entre a psicanálise e a categorização das deficiências, em busca de contribuir com a efetivação do direito à educação para as pessoas com deficiência.

\section{EDUCAÇÃO INCLUSIVA, DIGNIDADE E EFETIVIDADE PRESTACIONAL}

Dentre os direitos previstos a todas as pessoas no Brasil, de forma indistinta, encontra-se a educação, prevista como um direito fundamental social e subjetivo. Considerando-se que as pessoas com deficiência também são destinatárias dessa previsão, uma série de políticas públicas são veiculadas para garantir a educação inclusiva, independentemente da deficiência diagnosticada, conforme trabalham Nery da Silva e Mattiello (2020). ${ }^{3}$ Quando se trata da deficiência mental, porém, outros fatores podem ser invocados para maior compreensão do alcance das possibilidades e das limitações que assolam as pessoas com deficiência, como, por exemplo, a psicanálise.

Vincular a educação inclusiva e os estudos psicanalíticos, portanto, torna-se uma tarefa possível, desde que o liame seja tecido a partir da percepção multidisciplinar, como se pretende a seguir. A inclusão escolar das pessoas com deficiência é paradigmática da capacidade do estado de bem-estar de alcançar ou não, tanto em um nível puramente regulatório quanto no campo da eficácia, o "programa" constitucional (TROILO, 2012). Isso porque cabe ao Estado realizar as prestações que lhe são atribuídas legalmente ${ }^{4}$, de forma plena, cumprindo as determinações constitucionais, dentre as quais se destaca a prestação educacional.

Bucci (1997, p. 90) afirma, nesse sentido, que o Estado social se caracteriza por um “agir dos governos sob a forma de políticas públicas", segundo a qual a função estatal de coordenar as ações para a realização de direitos dos cidadãos se legitima pelo convencimento da sociedade quanto à necessidade de realização de direitos, inclusive dos direitos sociais, que

\footnotetext{
${ }^{3}$ Parte-se da premissa de que a efetivação dos direitos sociais para pessoas com deficiência exige a prestação de condições físicas e sociais aptas a propiciar o exercício de direitos, segundo lecionam.

${ }^{4}$ Considera-se, aqui, o conceito de "lei" lato sensu, da forma mais ampla e genérica possível, abrangendo toda e qualquer espécie normativa hábil a autorizar o agir do Estado, enquanto Administração Pública. É o que foi denominado por Freitas (2009, p. 70) de legalidade temperada, no sentido de que a Administração Pública deve pautar-se no Direito como "uma totalidade aberta, maior que o conjunto de regras legais", considerando-se que "o conteúdo jurídico, por força da natureza valorativa, transcende o mero e esparsamente positivado".
} 
possuem vértice prestacional ${ }^{5}$, destacando-se, nesse contexto, o direito fundamental social à educação.

No que tange à classificação dos direitos sociais em prestacionais ou não, salienta-se a previsão de Sarlet (2015) no sentido de que os direitos fundamentais podem ser classificados em razão de sua multifuncionalidade e não, apenas, estritamente conforme a sistemática do texto constitucional. Assim, a partir das funções por eles exercidas, os direitos fundamentais classificam-se em dois grandes grupos: os direitos de defesa e os direitos a prestações (de natureza fática e jurídica). Nesse segundo grupo, situam-se dois subgrupos, quais sejam, o dos direitos a prestações em sentido amplo e o dos direitos a prestações em sentido estrito. ${ }^{6}$

Bucci (1997) assevera que os direitos sociais, dentre o rol de direitos fundamentais do homem, efetivam-se por meio de prestações positivas do Estado. Para Abramovich e Courtis (2009, p. 6), porém, os direitos sociais (referindo-se, especificamente, aos direitos à saúde, moradia, educação e seguridade social) não se esgotam em prestações positivas, porque "al igual que en el caso de los derechos civiles, cuando los titulares hayan ya accedido al bien que constituye el objeto de esos derechos, el Estado tiene la obligación de abstenerse de realizar conductas que lo afecten".

Khaitan (2019), por sua vez, defende a necessidade de uma proteção robusta para implementação dos direitos sociais, inclusive com viável, justificada e cautelosa judicialização, como forma de auxiliar aqueles que estão na "base da escada econômica"7. Nery da Silva (2012), quanto a esse ponto, alerta para o fato de que a tomada de decisão acerca das escolhas públicas, muitas vezes, não implica necessariamente financiamento, pois há prioridades não vinculadas a custos.

\footnotetext{
${ }^{5}$ Nery da Silva (2012), quanto a esse ponto, aprofunda: "É imperioso lembrar que, além do foco direcionado aos direitos fundamentais e da inicial legitimação atribuída ao Estado, o aspecto econômico, referente ao financiamento das escolhas políticas estatais, pode assumir variados graus de importância, sendo relevante considerar seu potencial de constituir inconveniente e irremediável entrave à tomada das decisões".

${ }^{6}$ Segundo Sarlet (2015, p. 193): "Na doutrina, de modo especial na matriz germânica, utilizam-se também, talvez até com maior frequência, as expressões 'direitos de participação' ou 'direitos de quota-parte' (Teilhaberechte), como sinônimas do termo 'direito a prestações' (Leistungsrechte)”. Toma-se, aqui, a ideia de "direitos" sem afetar, de qualquer forma, a estrutura das normas de direitos fundamentais como princípios ou regras, na esteira da classificação de Robert Alexy (2015).

${ }^{7}$ Khaitan (2019) afirma: "A robust judicial protection of social rights, including the rights to shelter, education, nutrition, and other essentials, go some way in helping those at the bottom of the economic ladder. The theory and practice concerning judicial capacity with regard to the implementation of social rights is fairly sophisticated, and does not need revisiting here. Suffice it to say that a cautious and contained judicial enforcement of social rights is certainly viable, and justifiable".
} 
$\mathrm{Na}$ esfera educacional inclusiva, em específico, deve-se buscar não apenas a prestação com vistas a uma efetividade "formal", ou seja, pretendendo-se a inserção escolar por meio da matrícula da pessoa com deficiência em uma instituição de ensino. Trata-se de alcançar uma efetividade real, ou seja, substancial, com educação sendo prestada com qualidade, favorecendo a permanência da pessoa com deficiência no ambiente escolar e o seu melhor aproveitamento possível, dentro do quadro peculiar que cada deficiência pode ocasionar.

Trata-se de visualizar o processo educacional como movimento dialético de reflexão e crítica, com objetivo de transformação do mundo e de liberdade para educando, possibilitando-lhe decisão, escolha, autonomia, segundo preconiza Freire (1993). Essa liberdade que se expande ao âmbito privado não permite esquecer que o ensino, como resultante desses múltiplos vetores, é um dos componentes da educação e concorre à satisfação de um direito essencial dos seres humanos, de cuja realização depende a efetividade de vários outros direitos, consoante Wachsmann (2013).

Sobre o direito à educação configurar-se em um direito subjetivo, invocam-se as palavras de Garcia (2004), para quem tanto o direito objetivo como o subjetivo possuem um epicentro comum: a pessoa, natural ou jurídica, que é a titular em potencial das relações jurídicas que se desenvolvem no organismo social. Nessa linha de pensamento, enquanto o direito objetivo ocupa uma vertente externa à pessoa, mas a ela direcionada, o direito subjetivo se realiza na própria pessoa, razão de situar o direito à educação como direito subjetivo.

Além disso, alerta Gadotti (2009), o direito à educação não se limita às crianças e jovens, devendo-se abordar um direito associado - o direito à educação permanente - a ser prestado em condições de equidade e igualdade para todos. Assim, deve ser intercultural, integral e intersetorial, garantido pelo Estado, estabelecendo prioridade à atenção dos grupos sociais mais vulneráveis.

Sendo a sociedade o lugar em que a educação e seus atributos são desenvolvidos, ou seja, o lugar das oportunidades, pontua Maliska (2001), nela a educação é fator determinante. Nessa linha de pensamento, para que se possibilite o exercício desse direito, o Estado precisa aproveitar o potencial da sociedade civil na formulação de políticas públicas de educação e promover o desenvolvimento de sistemas solidários de educação, centrados, segundo Gadotti (2009), na cooperação e na inclusão. 
No que tange à educação especial, realmente, esse desenvolvimento deve estar apoiado pelo Estado (por meio de políticas adequadas), pela família (por intermédio de uma estrutura capaz de fornecer compreensão, afeto e estimulação constante) e, confirmando a tese defendida por Zanotto (2002), pelas instituições (por meio de ações educativas específicas, que incluem o desenvolvimento profissional docente), segundo o qual, esse processo envolve a habilidade de relacionar de forma coerente e sequencial três momentos: identificação de um problema, busca de explicação e proposição de soluções.

Maliska (2001) considera que a educação não apenas uma formação, mas uma condição formadora necessária ao próprio desenvolvimento natural. Liga-se, assim, a devida prestação educacional inclusiva com a dignidade da pessoa humana com deficiência, reforçando a concepção kantiana da dignidade de que a pessoa humana deve ser considerada como um fim em si mesma e em função da sua autonomia enquanto ser racional. Sob a égide desse pensamento, uma lei universal refutaria, de modo geral, a utilização do homem como meio para outro fim que não seja ele mesmo, na ótica de Kant (2004).

Para uma melhor compreensão do instituto a partir da noção kantiana, podem ser invocados os dizeres de Sarlet (2009), para quem a dignidade humana pode ser vista como um atributo intrínseco a cada ser humano que o faz distinto e merecedor do mesmo respeito e consideração por parte do Estado e da comunidade. Tal entendimento implica, por consequência, em reconhecer a necessidade de um complexo de direitos e deveres fundamentais aptos a assegurar a dignidade de todas as pessoas, em face de todo e qualquer ato de cunho degradante e desumano; implica em lhes garantir, ainda, as condições existenciais mínimas para uma vida saudável, além de propiciar e promover sua participação ativa nos destinos da própria existência e da vida, mediante o devido respeito aos demais.

E é a essa noção de dignidade que se liga a verdadeira inclusão. No sentido de promoção da inclusão e de análise dos resultados das medidas promovidas, convém ressaltar as palavras de Alvino-Borba e Mata-Lima (2011, p. 222), que, ao analisar a exclusão e a inclusão social nas sociedades modernas, afirmam que "exclusão social é um forte fator de preocupação da sociedade contemporânea e que, infelizmente, as políticas de inclusão não têm sido suficientes para fazer face aos imperativos sociais".

Nussbaum (2013), em sentido complementar, esclarece que um dos problemas pendentes de resolução na sociedade funda-se na justiça social para pessoas com impedimentos físicos e mentais. Ou seja, algumas capacidades são tão importantes para a vida 
humana que, em caso de falta de qualquer uma delas, não se configuraria uma vida humana com dignidade, o que inclui, por óbvio, o exercício do direito à educação.

Embora não se destine a fornecer explicações completas sobre a justiça social, o enfoque das capacidades (NUSSBAUM, 2013) é capaz de supri-las, mediante um olhar mais próximo à realidade das pessoas com deficiência. Para a autora, a aceitação das terminologias "impedimentos" e "deficiências" em suas diferentes concepções, frisando haver, pelo menos, duas formas de compreender a deficiência: a primeira, a entender como uma manifestação da diversidade humana, entendendo-se que um corpo com impedimentos é o de alguém que vivencia impedimentos de ordem física, intelectual ou sensorial ${ }^{8}$ (essa ideia correspondente ao modelo social da deficiência, por meio do qual a garantia da igualdade entre pessoas com e sem impedimentos corporais não deve se resumir a critérios biomédicos); já a segunda, entende a deficiência como uma desvantagem natural, devendo os esforços se concentrarem em reparar os impedimentos corporais, a fim de garantir a todas as pessoas um padrão de funcionamento típico à espécie.

A tese central do modelo social permitiu o deslocamento do tema da deficiência dos espaços domésticos para a vida pública, até porque a deficiência não é matéria de vida privada ou de cuidados familiares, mas uma questão de justiça, segundo Nussbaum (2013). Ademais, como fundamento constitucional brasileiro da dignidade da pessoa humana, Strapazzon e Tramontina (2017, p. 31), pontuam que a dignidade é o núcleo originário da perspectiva nussbauniana, já as capacidades são sua linguagem e categoria central.

Com isso, a inclusão social recebe outra concepção, constituindo-se como um processo bilateral pelo qual "a sociedade se adapta para poder incluir, em seus sistemas sociais gerais, pessoas com deficiência (além de outras) e, simultaneamente, estas se preparam para assumir seus papeis na sociedade", nas palavras de Sassaki (2010, p. 39-46). O autor delineia os conceitos 9 de "impedimento" (impairment), "deficiência" (disability) e "incapacidade" (handicap), a partir dos quais se depreende que as pessoas, ainda em situação

\footnotetext{
${ }^{8}$ Nessa análise, não se pode afastar a ideia de Nussbaum (2013) de que as barreiras sociais, ao ignorar os corpos com impedimentos, provocam a experiência da desigualdade, sendo a opressão não um atributo dos impedimentos corporais, mas resultado de sociedades não inclusivas.

${ }^{9}$ Os conceitos de impedimento, deficiência e incapacidade são assim diferenciados, segundo a Organização Mundial de Saúde (OMS): impedimento é "qualquer perda ou anormalidade da função ou estrutura psicológica, fisiológica ou anatômica"; deficiência, "qualquer restrição ou falta (resultante de um impedimento) da habilidade para desempenhar uma atividade de uma maneira, ou com variância, considerada normal para um ser humano"; e incapacidade, "uma desvantagem, resultante de um impedimento ou de uma deficiência, que limita ou impede a realização de um papel considerado normal para um dado indivíduo", tomadas as variáveis de idade, sexo e fatores sociais e culturais.
} 
de excluídas, assim como a sociedade busquem equacionar os problemas em parceria, ao mesmo tempo em que decidem sobre possíveis soluções e buscam efetivar a equiparação de oportunidades para todos.

A propósito das fases atinentes ao processo de inclusão, Sassaki (2010) elenca cronologicamente as fases de exclusão, segregação institucional, integração e inclusão. Por fase de exclusão, tem-se aquela em que nenhuma atenção educacional foi dispensada às pessoas com deficiência. Estas sofriam com a rejeição e a exploração pela sociedade, pois eram consideradas possuídas por maus espíritos ou como vítimas de feitiçaria e influências do gênero. Na fase de segregação institucional, as pessoas com deficiência eram atendidas por instituições, evidenciando-se cunho filantrópico ou religioso em tais segregações. Foi o surgimento da educação especial, em escolas instituídas como centros de reabilitação e oficinas de trabalho.

Percebeu-se, a partir de então, um olhar diferenciado da sociedade para as pessoas com deficiência, como passíveis de escolarização e de treinamento profissional. Sassaki (2010) afirma que a fase de integração marcou pelo surgimento de classes especiais nas escolas comuns, para atendimento das pessoas com deficiência. Esclarece ainda que a grande mudança na sociedade surgiu com a percepção de que não bastava adaptar as pessoas à sociedade, mas, sim, adaptar a sociedade às pessoas com deficiência.

A dicotomia entre o normal e o patológico, representada pela oposição entre o corpo sem e com impedimentos, permitiu a consolidação do combate à discriminação como objeto de intervenção política, tal como previsto pela Convenção das Nações Unidas sobre os Direitos das Pessoas com Deficiência (BRASIL, 2009), ratificada pelo Brasil em 2008 e promulgada no Brasil em 2009 pelo Decreto n. 6.949, com status de emenda constitucional ${ }^{10}$, na forma do art. $5^{\circ}, \S 3^{\circ}$, da Constituição da República (BRASIL, 1988). Como resultado das discussões internacionais entre os modelos biomédico e social, referido instrumento define as pessoas com deficiência como "aquelas que têm impedimentos de natureza física, intelectual ou sensorial, os quais, em interação com diversas barreiras, podem obstruir sua participação plena e efetiva na sociedade com as demais pessoas" (BRASIL, 2009).

A Convenção da Organização das Nações Unidas - ONU enfatiza a perspectiva de que se deve reconhecer a deficiência como um "conceito em evolução", segundo seu

\footnotetext{
${ }^{10}$ Conferiu-se patamar relevante à Convenção da ONU sobre as Pessoas com Deficiência, tendo sido esse o primeiro diploma internacional a ser aprovado no Brasil com status de Emenda Constitucional, nos termos do parágrafo $3^{\circ}$ do artigo $5^{\circ}$ da Constituição da República Federativa do Brasil de 1988.
} 
preâmbulo. Impõe-se, assim, olhar a deficiência como resultado de uma interação, propiciada em maior ou menor grau, das pessoas com impedimentos e obstáculos, sejam ambientais ou comportamentais (BRASIL, 2009). Significa dizer que a deficiência somente será assim considerada se impedir a inclusão plena e a efetiva participação das pessoas na sociedade com fulcro nas oportunidades com os demais, se estas não forem iguais. E essa concepção não pode ser afastada quando se trata de educação.

A educação pode ser vista como atividade com potencial de modificação da história de vida de cada pessoa. Este tema é encarado pela ótica da denominada "Educação de Qualidade", cuja origem se assenta na Agenda 2030 para o Desenvolvimento Sustentável, adotada na Conferência de Nova Iorque de 2015.

O hoje conhecido e consagrado "desenvolvimento sustentável" constituiu a pauta da Conferência de Nova Iorque da Organização das Nações Unidas para o Meio Ambiente, de setembro de 2015. Dessa conferência participaram 193 (cento e noventa e três) estadosmembros da ONU, que adotaram 17 (dezessete) Objetivos do Desenvolvimento Sustentável ODS, estimulados em promover o desenvolvimento por meio de 5 (cinco) ou vertentes áreas de importância, que ficaram conhecidas como "5P" (People, Prosperity, Peace, Partnership e Planet), a saber: (1) Pessoas; (2) Prosperidade; (3) Paz; (4) Parcerias e (5) Planeta. Para o atendimento desses 17 "ODS”, foram estabelecidas 169 (cento e sessenta e nove) "metas".

A ideia, portanto, de "educação de qualidade", constitui adjetivação trazida pelo ODS n. 4, dessa Agenda: "Assegurar a educação inclusiva e equitativa de qualidade e promover oportunidades de aprendizagem ao longo da vida para todos", que tem por ideia central a inclusão e a oferta de oportunidades equitativas para todos os brasileiros.

Especial destaque deve ser dado à dita "promoção de oportunidades de aprendizagem ao longo da vida para todos", pois em que pese a ideia de universalizar o ensino "para todos" não ser uma novidade, o diferencial se faz na expressão agregada "ao longo da vida", que, sem dúvida constitui inovação ao configurar uma nova amplitude ao compromisso dos Estados-membros para com seus governados, vale dizer, um dever de prover continuadamente alternativas educacionais, ao longo de suas vidas, principalmente àqueles que não tiverem tido acesso às precedentes em outros momentos de suas vidas pessoais.

A partir dessas considerações, torna-se imperativo analisar a concretização dos direitos previstos para as pessoas com deficiência, considerando-se que eventuais impedimentos e deficiências permitem constatação direta no agir diário, conforme os fatores 
socioambientais que interferem no agir em sociedade, inclusive quanto ao que reflete na prática educacional. Assim, importa ao presente estudo conhecer o número de pessoas com deficiência no Brasil.

No censo decenal do Instituto Brasileiro de Geografia e Estatística - IBGE de 2010, em que 191 (cento e noventa e um) mil recenseadores visitaram 67,6 (sessenta e sete vírgula seis) milhões de domicílios nos 5.565 (cinco mil, quinhentos e sessenta e cinco) municípios brasileiros, apontou-se que quase 46 (quarenta e seis) milhões de pessoas declararam ter pelo menos uma das deficiências investigadas, o que corresponde a cerca de $24 \%$ (vinte e quatro por cento) da população brasileira (IBGE, 2010).

O censo procurou identificar o número de pessoas com deficiências visual, auditiva e motora, considerando os graus de severidade das deficiências, e a deficiência mental ou intelectual, tendo como marco conceitual a Classificação Internacional de Funcionalidade, Incapacidade e Saúde - CIF divulgada pela Organização Mundial da Saúde - OMS em 2001.

Em 2018, porém, o IBGE divulgou a Nota técnica 01/2018, anunciando uma releitura dos dados de pessoas com deficiência no Censo Demográfico 2010 à luz das recomendações do Grupo de Washington (IBGE, 2018) ${ }^{11}$. O IBGE realizou estudos que buscaram avaliar e validar o conjunto de perguntas propostas pelo Grupo de Washington para Estatísticas sobre Pessoas com Deficiência (Washington Group on Disability Statistics - WG) vinculado à Divisão de Estatísticas do Departamento de Assuntos Econômicos e Sociais das Nações Unidas e criado com o intuito de fomentar a cooperação internacional no âmbito das estatísticas de pessoas com deficiência. Conforme divulgado pelas Nações Unidas, com o objetivo principal de informar a política de equalização de oportunidades, o WG desenvolveu, testou internacionalmente e adotou o Short Set on Functioning (WG-SS) composto de seis medidas de deficiência adequadas para uso em censos, pesquisas nacionais baseadas em amostra ou outros instrumentos estatísticos (UN, 2021). ${ }^{12}$

\footnotetext{
${ }^{11}$ O Grupo de Washington busca padronizar e harmonizar definições, conceitos e metodologias de modo a garantir a comparabilidade das estatísticas entre diferentes países. É formado sob a Comissão de Estatística das Nações Unidas e composto por representantes de Institutos Oficiais de Estatística e organizações representantes da sociedade civil. Como representante oficial do Brasil, o IBGE participa desde o início da formação do grupo, em 2001, acompanhando as discussões e estudos propostos (Fonte: IBGE, 2018).

${ }^{12}$ Estudos desenvolvidos pelo Grupo de Washington apuraram, por exemplo, que as pessoas classificadas nos resultados do Censo 2010 como "pessoas com deficiência severa" foram o principal alvo das políticas públicas voltadas para a população com deficiência (IBGE, 2018) e que as pessoas com deficiência foram um dos subgrupos mais afetados negativamente pela pandemia (UN, 2021).
} 
Ao aplicar a linha de corte utilizada pelo Grupo de Washington, a população total de pessoas com deficiência residentes no Brasil captada pela amostra do Censo Demográfico 2010 não se faz mais representada pelas 45.606.048 (quarenta e cinco milhões, seiscentos e seis mil e quarenta e oito) pessoas, ou 23,9\% (vinte e três vírgula nove por cento) das 190.755.048 (cento e noventa milhões, setecentos e cinquenta e cinco mil e quarenta e oito) pessoas recenseadas nessa operação censitária, mas, sim, por um quantitativo de 12.748.663 (doze milhões, setecentos e quarenta e oito mil, seiscentos e sessenta e três) pessoas, ou 6,7\% (seis vírgula sete) do total da população registrado pelo Censo Demográfico 2010 (IBGE, 2018).

Esses números, tanto os anteriores quanto os posteriores à reanálise, são determinantes para a implementação de políticas públicas de educação inclusiva direcionadas às pessoas com deficiência, em especial a quantidade de pessoas com deficiência, ou com deficiências, assim identificadas após a reanálise feita pelo IBGE, já que a aplicação dos critérios do Grupo de Washington objetiva o alinhamento com as práticas internacionais e a comparabilidade com outros países realizada pela Organização das Nações Unidas.

Troilo (2012) registra que o reconhecimento do direito à educação de qualidade para as pessoas com deficiência é crescente em âmbito global ${ }^{13}$. Mattiello (2016), porém, ressalva que, no Brasil, a problemática adquire proporção significativa, uma vez que as políticas educacionais inclusivas não têm alcançado o desiderato de garantir a plena efetividade educacional para as pessoas com deficiência, a qual deve ser perseguida para que a inclusão, em sua essência, ocorra no seu verdadeiro e pleno sentido. Nesse sentido, a sociedade deve se adaptar para promover a inclusão, pelo respeito e atendimento às peculiaridades e às necessidades especiais que, de fato, configurem deficiências.

Do até aqui observado, conclui-se, parcialmente que a educação deve ser assegurada não apenas por se tratar de um direito elencado como fundamental na Constituição brasileira,

\footnotetext{
${ }^{13}$ Troilo (2012) destaca sobre o contexto europeu: “[...] recentemente si sono dovuti pronunciare in merito $i$ supremi organi giudiziari di due fra i più importanti Paesi europei. Mentre nel Regno Unito la Corte Suprema ha ritenuto che l'ordinamento, pur riconoscendo il diritto all'istruzione dei disabili, non offra una garanzia assoluta a ricevere un certo tipo o una certa qualità di istruzione e che, per conseguenza, non possa farsi discendere dalla normativa vigente (nemmeno dalla Convenzione europea dei diritti dell'uomo, incorporata nel Paese con lo Human Rights Act del 1998) un obbligo, per la pubblica amministrazione, di offrire forme particolari di inserimento scolastico a persone con speciali necessità, prescindendo dalla limitatezza delle risorse disponibili, in Francia il Consiglio di Stato ha invece affermato che lo Stato ha l'obbligo di predisporre tutte le misure necessarie per garantire l'effettività del diritto all'istruzione degli studenti handicappati considerato assoluto - e che, qualora non vi riesca, risponde dei danni procurati, dovendo indennizzare le famiglie che si siano sobbarcate il costo di soluzioni alternative per garantire l'istruzione dei loro figli."
} 
mas por ser elemento integrativo da dignidade de todas as pessoas humanas, tendo elas, ou não, alguma deficiência. Assim, a efetividade do direito à educação depende de políticas públicas substancialmente inclusivas, para que se promova uma real inclusão. Políticas educacionais que incluem as pessoas com deficiência em caráter meramente formal não contribuem para que a educação seja prestada no seu real sentido, com vistas a garantir o conhecimento fomentador da equiparação de oportunidades.

\section{PSICANÁLISE E PESSOAS COM DEFICIÊNCIA: O NEXO POSSÍVEL}

Desvendar a ligação entre o obscuro na mente humana e seus reflexos na intelectualidade - a ponto de se verificar que alguns transtornos culminam no que se considera deficiência mental ou outras psicopatologias - é um tema instigante e que merece esclarecimentos multidisciplinares, como se faz no presente estudo, vinculando a educação inclusiva e a psicanálise.

Apesar de, inicialmente, parecer um contrassenso, uma vez que a psicanálise trabalha por meio de estruturas discursivas (formas construídas para responder ao desejo do outro), enquanto as deficiências mentais e outros problemas de ordem orgânica podem ser aferidos por exames (já que pertencentes ao âmbito do biológico), tal nexo pode ser construído.

Um dos grandes desafios da ciência, nos últimos séculos, foi descobrir que, nem sempre, as pessoas têm exclusiva consciência sobre seu corpo, seus sentimentos, suas vontades e seu agir. Isso porque se percebeu, ao longo dos anos, que muitos dos sentimentos a atos perpetrados têm origem no inconsciente. Nesse contexto, percebe-se uma relação (distante?) entre a aplicação de conceitos de psicanálise e as deficiências, em especial no que tange à categorização da deficiência mental.

De Lacan (2011) advém que as manifestações clínicas da psicose, como a paranoia, a melancolia e a esquizofrenia não são doenças. Embora se apresentem com sintomas relacionados a delírios e alucinações, partindo-se da ideia de que o corpo biológico não pode ser confundido com o sujeito, tratar-se-iam de montagens construídas nos processos de reconhecimento do desejo, assim como a perversão, por ser algo não inato.

Diferenciando-se o sujeito da psicanálise com o sujeito de direito, pode-se afirmar que ser sujeito no âmbito jurídico equivale a ter autonomia e opções de escolha - daí a dificuldade inicial de vislumbrar, nesse panorama, eventual nexo dos conceitos relacionados à 
psicanálise com o estudo das deficiências. A questão, porém, merece análise cuidadosa vinculada às modernas concepções de deficiência.

Segundo se denota das publicações contidas no volume I das Obras psicológicas completas de Sigmund Freud, ainda no período considerado pré-psicanalítico, Freud, ocasião de seus estudos no Hospital da Salpêtrière em Paris, aproximou-se de casos que evidenciaram a presença de patologias oriundas não do corpo físico, mas de algum lugar da mente humana. Segundo os estudos do médico e cientista francês Jean-Martin Charcot, cujos ensinamentos foram por Freud compartilhados, percebeu-se a importância da fala e seus distúrbios nas narrativas dos pacientes, passando a ser visto o aparelho de linguagem como um aparelho psíquico.

Freud (1996b) afirma que as palavras de Charcot eram no sentido de que, encerrado o trabalho da anatomia, a teoria das doenças orgânicas do sistema nervoso podia ser dada como completa, devendo-se considerar, em seguida, as neuroses do(s) paciente(s). A partir de então, seu trabalho centralizou-se quase por completo nas neuroses, principalmente na histeria. Garcia-Roza (2009, p. 32-33), por sua vez, esclarece que "ao produzir a separação da histeria com respeito à anatomia patológica, Charcot a introduziu no campo das perturbações fisiológicas do sistema nervoso".

Porém, com o passar do tempo, apresentar uma sintomatologia regular para a histeria continuava sendo a questão problemática. Isso porque, caso fosse alcançado tal intento, a histeria seria incluída no campo das doenças neurológicas; do contrário, "o histérico seria identificado ao louco", persistindo a ideia do "diagnóstico diferencial versus diagnóstico absoluto", nas palavras de Garcia-Roza (2009, p. 33). A histeria foi conceituada por Freud (1996b, p. 36) como sendo "uma neurose no mais estrito sentido da palavra - quer dizer, não só não foram achadas nessa doença alterações perceptíveis do sistema nervoso, como também não se espera que qualquer aperfeiçoamento das técnicas de anatomia venha a revelar alguma dessas alterações".

Em Publicações pré-psicanalíticas e esboços inéditos, ainda, Freud (1996b, p. 36) considerou a histeria sob uma visão mais neurológica, sem a vincular com a ótica da linguagem, salientando que se baseia "total e inteiramente em modificações fisiológicas do sistema nervoso". Afirmou que "sua essência deve ser expressa numa fórmula que leve em consideração as condições de excitabilidade nas diferentes partes do sistema nervoso", frisando, porém, que até então não havia sido descoberta "uma fórmula fisiopatológica desse 
tipo" Ao abordar a sintomatologia da histeria, Freud (1996b) esclareceu aspectos importantes sobre ataques convulsivos, zonas histerógenas, distúrbios da sensibilidade, distúrbios da atividade sensorial, paralisias, contraturas, dentre outros sintomas gerais que comumente são associados à deficiência mental.

Afirmou ser "especialmente característico da histeria que seja um distúrbio, ao mesmo tempo, desenvolvido no mais alto grau e limitado da maneira mais nítida”, ou seja, aquilo que se pode chamar de conversões histéricas. Afirmou, também, que "os sintomas histéricos mudam de uma forma que, de saída, exclui qualquer suspeita de lesão orgânica" e que tal mutabilidade dos sintomas "realiza-se ou espontaneamente (por exemplo, depois de ataques convulsivos, que muitas vezes alteram a distribuição da paralisia e da anestesia, ou as interrompem) ou por influência artificial dos chamados métodos estesiogênicos", segundo Freud (1996b, p. 42).

Outra contribuição importante de Freud para os estudos entrelaçados da psicanálise com as deficiências oriundas da psicopatologia reside da ideia da pulsão (trieb). Em momento posterior de seus escritos, Freud (1996a, p. 142) considerou a pulsão como "um conceito situado na fronteira entre o mental e o somático", bem como "representante psíquico dos estímulos que se originam dentro do organismo e alcançam a mente".

Freud, inicialmente, abordou a pulsão de vida e a pulsão sexual. Após, não mais as separou, tratando-as conjuntamente, como desdobramentos da mesma energia (diferenciando, por certo, as pulsões de vida e de morte). Com essas premissas, indaga-se: como a pulsão transita no inconsciente, passando ao pré-consciente e indo ao consciente? E, nesse panorama, onde se situam as patologias e, eventualmente, as deficiências?

Em As Pulsões e seus Destinos, Freud (1996a) conceituou a pulsão como um estímulo interno, por ser uma reação físico-química do corpo, situando-a como um fenômeno limítrofe entre o somático e o psíquico. Na pulsão, as forças impulsionadoras originadas no interior do corpo são transmitidas ao aparelho mental (psique), pressionando no sentido de descarga. Para que a pulsão seja extravasada, deve ser representada como um objeto (objeto do desejo). Ao longo da vida, esse objeto de desejo vai mudando, configurando-se em representante reativo da pulsão (um investimento da pulsão em determinado objeto, para Freud).

Seguindo essa linha de raciocínio, tem-se que, para passar ao consciente, para extravasar, a ideia passa pelo recalque (salienta-se: a repressão é do eu; o recalque é do 
inconsciente). Se a ideia não está de acordo com o que se admitiria, há um bloqueio: o recalque (a ideia fica bloqueada no inconsciente). A ideia precisa romper a resistência do eu; está recalcada, vale dizer, negada no eu, mas permanece como associação no inconsciente. Vem, pois, ao consciente através das formações do inconsciente, que rompem essa barreira. Porém, o afeto não fica bloqueado, ligando-se a outra ideia substitutiva.

Assim, o papel do pré-consciente é de uma espécie de censura: se a ideia for algo compatível com o consciente, ela "passa"; se for incompatível, "fica", mas o afeto segue. Com a supressão, gera-se angústia. Com o deslocamento do afeto, reprimindo-se a ideia, podem surgir as fobias, a produção de sintomas, a somatização. Nesse ponto é que pode se verificar o surgimento de psicopatologias, que, efetivamente, geram sofrimento, ainda que sem uma causa física.

A somatização pode manifestar-se de diversas formas, permitindo-se adentrar, inclusive, no universo dos estudos da perversão, no que tange às manifestações e aos sintomas apresentados. Por mais que se tenha alterado, ao longo dos séculos, a ideia do que é a perversão e de quem são os perversos (ROUDINESCO, 2008), certo é que a evidência de sintomatologia relacionada à perversão e suas manifestações conduziam as "vítimas" de psicopatologias ao patamar de anormais, loucos inumamos, dentre outras designações costumeiramente impingidas aos deficientes mentais.

No que tange à histeria, especificamente, Freud referiu que nem todos os histéricos apresentam sintomas psíquicos, fazendo alusão ao inconsciente ${ }^{14}$, nas seguintes palavras: “Os sintomas psíquicos têm sua significação dentro do quadro total da histeria, mas não são mais constantes do que os diferentes sintomas físicos, os estigmas". E continuou: "Por outro lado, as modificações psíquicas, que devem ser assinaladas como o fundamento do estado histérico, ocorrem inteiramente na esfera da atividade cerebral inconsciente, automática" (FREUD, 1996b, p. 46).

A partir dessa concepção, considerando-se a relação entre o inconsciente e a produção sintomatológica, abrem-se portas para o estudo das deficiências, especialmente para a categorização contida no ambiente normativo brasileiro. $\mathrm{O}$ art. $5^{\circ}$, I, do Decreto $\mathrm{n}$. 5.296/2004 conceitua pessoa com deficiência como sendo aquela que possui limitação ou

\footnotetext{
${ }^{14}$ Garcia-Roza (2009, p. 169-170) pontua que o termo inconsciente, ao ser empregado antes de Freud, designava, de forma puramente adjetiva, o que não era consciente, sem a pretensão de assinalar um "sistema psíquico distinto dos demais e dotado de atividade própria". O inconsciente freudiano, porém, é tratado como um lugar psíquico, que contém representações - mais especificamente, "representações psíquicas da pulsão.
} 
incapacidade para o desempenho de atividade e se enquadra nas seguintes categorias: (a) deficiência física; (b) deficiência auditiva; (c) deficiência visual; (d) deficiência mental; e (e) deficiência múltipla - associação de duas ou mais deficiências (BRASIL, 2004).

Conforme tal normativa, a deficiência mental equivale a funcionamento intelectual com limitações associadas a duas ou mais áreas de habilidades adaptativas, tais como ais como: comunicação; cuidado pessoal; habilidades sociais; utilização dos recursos da comunidade; saúde e segurança; habilidades acadêmicas; lazer; e trabalho; (BRASIL, 2004). Ainda, a partir da Lei n. 12.764/2012, as pessoas com transtorno do espectro autista - TEA passaram a ser consideradas pessoas com deficiência, por apresentarem deficiência significativa na comunicação e na interação social (BRASIL, 2012). ${ }^{15}$

A referida categorização convive com o conceito de deficiência que se encontra em evolução no Brasil, buscando adequar-se com o que preceitua a Convenção Internacional sobre os Direitos das Pessoas com Deficiência e seu Protocolo Facultativo, promulgada no Brasil com o Decreto n. 6.949/2009. Uma visão mais atual coadunada com os dizeres da Convenção propõe um conceito de deficiência que reconhece o impedimento das pessoas no convívio social em detrimento de critérios biológicos (BRASIL, 2009), o que evidencia cada vez mais a importância dos elementos psíquicos na categorização.

Do exposto, evidencia-se que a psicanálise pode contribuir para o diagnóstico adequado quando se trata da categorização das deficiências, considerando-se que um corpo com impedimentos é o de alguém que vivencia reais impedimentos de ordem física, intelectual ou sensorial. A partir da concepção do modelo social da deficiência, os saberes psicanalíticos podem afastar ou confirmar determinados diagnósticos, com base na análise da produção sintomatológica e das psicopatologias que são objeto de estudo da psicanálise. Por via de consequência, no sentido de que a garantia da igualdade entre pessoas com e sem impedimentos corporais não deve se resumir a critérios biomédicos, essa contribuição pode ser decisiva na definição das políticas de educação inclusiva que sejam mais adequadas para que as pessoas com deficiências alcancem uma educação de qualidade.

\section{CONCLUSÃO}

\footnotetext{
${ }^{15}$ Não à toa, termos como autismo, loucura, paranoia e outros relacionados a deficiências mentais encontram-se definidos nos dicionários específicos de termos psicanalíticos, oportunizando discussões nesse campo. A exemplo, situam-se como verbetes no Dicionário de Psicanálise de Roudinesco e Plon (1998).
} 
O direito à educação possui alicerce constitucional e somente pode se efetivar por meio de políticas públicas que lhe confiram concretização, especialmente quando se trata de pessoas com deficiência. A partir do estudo realizado, constata-se que, não apenas em âmbito global, no Brasil existem políticas de educação, cada vez mais preocupadas com a inclusão pela política educacional devida a todos, de forma indistinta, como garantia de autonomia promotora de dignidade e do exercício de liberdades constitucionais.

A pesquisa demonstrou que o Brasil adotou a conceituação proposta pela Convenção da ONU sobre os Direitos das Pessoas com Deficiência, a qual leva em conta, para diagnosticar as deficiências, a existência ou não de impedimentos capazes de obstruir a participação efetiva e plena das pessoas no convívio social. Por se tratar a educação de atividade que exige o exercício dos sentidos, da linguagem e da interação, a hipótese de sua não prestação efetiva às pessoas com deficiência se mostra ainda mais grave, o que permite concluir que nesse mister o Estado não cumpriu seu dever de educar para incluir.

$\mathrm{Na}$ gama de motivos ensejadores dessa inefetividade, o presente estudo apontou a adoção de políticas públicas insuficientes e a não utilização de formas adequadas de diagnosticar ou categorizar as deficiências, dentre outros fatores que podem ser determinantes para a falta de concretização dos direitos das pessoas com deficiência. Nesse ponto, encontrou-se na psicanálise importante elemento auxiliar e capaz de gerar maior compreensão sobre a gênese de algumas manifestações relacionadas às deficiências mentais e/ou a outros impedimentos sensoriais, por exemplo.

A categorização das deficiências adotada legalmente, ainda que imbuída de evidentes características biológicas, considera sintomas e manifestações que são estudados em psicanálise. Esta, entretanto, vai muito além, pois a análise levada em conta na categorização talvez não disponha de precisão teórica apta a apurar a origem, as fronteiras e os porquês dos impedimentos à socialização. Sendo a psicanálise uma forma de tratamento terapêutico destinada a pessoas capazes, apurou-se não ser crível, inicialmente, falar em "inconsciente deficiente"; porém, as formas de manifestação das psicopatologias a partir da somatização, gerada pela repressão das ideias e pelo deslocamento dos afetos, podem ocasionar sintomas mais ou menos graves passíveis de diagnósticos relacionados à deficiência mental, em severidade de maior ou menor grau, conforme o nível de impedimentos para socialização.

Nesse ponto, os estudos psicanalíticos contribuem sobremaneira, na medida em que as deficiências, na visão atualmente reconhecida e aplicável a partir da Convenção da ONU 
sobre os Direitos das Pessoas com Deficiência, são consideradas conforme o nível de impedimentos de natureza física, intelectual ou sensorial que podem obstruir a participação das pessoas, de forma plena e efetiva, na sociedade com as demais pessoas, em interação com diversas barreiras.

Se ser sujeito, no âmbito do direito, importa em ter autonomia, não se pode afastar a aproximação de conceitos iniciais da psicanálise com a categorização das deficiências, já que a repressão (do eu) e o recalque (do inconsciente) podem causar a produção de sintomas, a somatização e as perturbações daí decorrentes, com eventual diagnóstico psicopatológico relacionado a um ou mais impedimentos.

A partir do momento em que a pessoa fica incapaz de exercer as possibilidades de linguagem e de interação, a ponto de afastar-se do convívio social, das práticas de ensino e da autonomia conferida pelo pleno discernimento, tem-se, como consequência, a inefetividade do seu direito à educação. Mesmo que existam políticas educacionais inclusivas aptas a inserir essa pessoa, formalmente, no ambiente escolar, se daí não advier o real sentido da educação como condição formadora do conhecimento e fomentadora da autonomia, ainda se estará falando em inefetividade.

\section{REFERÊNCIAS}

ABRAMOVICH, Victor; COURTIS, Christian. Apuntes sobre la exigibilidad judicial de los derechos sociales. In: Courtis, Christian; Santamaría, Ramiro Ávila. La protección judicial de los derechos sociales. 1ªed. V\&M Gráficas. Quito, Ecuador: 2009. P. 3-29.

ALEXY, Robert. Teoria dos direitos fundamentais. Trad. Virgílio Afonso da Silva. $2^{\mathrm{a}}$ ed., $4^{\mathrm{a}}$ tir. São Paulo: Malheiros, 2015.

ALVINO-BORBA, Andreilcy; MATA-LIMA, Herlander. Exclusão e inclusão social nas sociedades modernas: um olhar sobre a situação em Portugal e na União Europeia. Revista Serviço Social \& Sociedade, São Paulo, n. 106, p. 219-240, abr./jun. 2011.

BRASIL. [Constituição (1988)]. Constituição da República Federativa do Brasil de 1988. Diário Oficial da União, Brasília, DF, 5 out. 1988. Disponível em: http://www.planalto.gov.br/ccivil_03/constituicao/constituicao.htm. Acesso em:

BRASIL. Decreto n. 5.296, de 2 de dezembro de 2004. Regulamenta as Leis n. 10.048, de 8 de novembro de 2000, que dá prioridade de atendimento às pessoas que especifica, e 10.098, de 19 de dezembro de 2000, que estabelece normas gerais e critérios básicos para a promoção da acessibilidade das pessoas portadoras de deficiência ou com mobilidade reduzida, e dá outras providências. Diário Oficial da União, Brasília, DF, 3 dez. 2004. Disponível em: 
http://www. planalto.gov.br/ccivil_03/_Ato2004-2006/2004/Decreto/D5296.htm. Acesso em: 2 ago. 2020.

BRASIL. Decreto n. 6.949, de 25 de agosto de 2009. Promulga a Convenção Internacional sobre os Direitos das Pessoas com Deficiência e seu Protocolo Facultativo, assinados em Nova York, em 30 de março de 2007. Diário Oficial da União, Brasília, DF, 26 ago. 2009. Disponível em: http://www.planalto.gov.br/ccivil_03/_ato2007-2010/2009/ decreto/d6949.htm. Acesso em: 2 ago. 2020.

BRASIL. Lei n. 12.764, de 27 de dezembro 2012. Institui a Política Nacional de Proteção dos Direitos da Pessoa com Transtorno do Espectro Autista; e altera o $\S 3^{\circ}$ do art. 98 da Lei n. 8.112, de 11 de dezembro de 1990. Diário Oficial da União, Brasília, DF, 28 dez. 2012. Disponível em: http://www.planalto.gov.br/ccivil_03/_ato2011-2014/2012/lei/112764. htm. Acesso em: 2 ago. 2020.

BUCCI, Maria Paula Dallari. Políticas públicas e direito administrativo. Revista de Informação Legislativa. Brasília, v. 34, n. 133, p. 89-98, jan./mar. 1997. Disponível em: http://www2.senado.leg.br/bdsf/item/id/198. Acesso em: 05.ago.2015.

FREIRE, Paulo. Política e educação. Coleção Questões da nossa época. São Paulo: Cortez Editora, 1993.

FREITAS, Juarez. $O$ controle dos atos administrativos e os princípios fundamentais. $4^{\text {a }}$ ed. São Paulo: Malheiros, 2009.

FREUD, Sigmund. A história do movimento psicanalítico, artigos sobre metapsicologia e outros trabalhos [1914-1916]. In: FREUD, Sigmund. Edição standard brasileira das obras psicológicas completas de Sigmund Freud. Rio de Janeiro: Imago, 1996a. v. XIV.

FREUD, Sigmund. Publicações pré-psicanalíticas e esboços inéditos [1886-1899]. In: FREUD, Sigmund. Edição standard brasileira das obras psicológicas completas de Sigmund Freud. Rio de Janeiro: Imago, 1996b. v. 1.

GADOTTI, Moacir. Educação de adultos como direito humano. São Paulo: Instituto Paulo Freire, 2009.

GARCIA, Emerson. O Direito à Educação e suas Perspectivas de Efetividade. In: Revista Jurídica Virtual. Vol. 5, n. 57. Fev.2004. Disponível em:

http://www.planalto.gov.br/ccivil_03/revista/Rev_57/Artigos/Art_Emerson.htm. Acesso em: 03.mar.2015.

GARCIA-ROZA, Luiz Alfredo. Freud e o inconsciente. 24. ed. Rio de Janeiro: Jorge Zahar Ed., 2009.

HÄBERLE, Peter. A dignidade humana como fundamento da comunidade estatal. In:

SARLET, Ingo Wolfgang (Org.). Dimensões da dignidade: ensaios de filosofia do direito e direito constitucional. 2. ed, rev. et ampl. Porto Alegre: Livraria do Advogado, 2009, pp. 45103. 
IBGE - Instituto Brasileiro de Geografia e Estatística. Censo demográfico: características gerais da população, religião e pessoas com deficiência. 2010. Disponível em:

http://biblioteca.ibge.gov.br/visualizacao/periodicos/94/cd_2010_religiao_deficiencia.pdf. Acesso em: 30 jul.2020.

IBGE - Instituto Brasileiro de Geografia e Estatística. Nota técnica 01/2018: releitura dos dados de pessoas com deficiência no Censo Demográfico 2010 à luz das recomendações do Grupo de Washington. 2018. Disponível em:

https://ftp.ibge.gov.br/Censos/Censo_Demografico_2010/metodologia/notas_tecnicas/nota_te cnica_2018_01_censo2010.pdf. Acesso em: 2 out.2021.

KHAITAN, Tarunabh. Political insurance for the (relative) poor: how liberal constitutionalism could resist plutocracy. Global Constitutionalism, v. 8, 2019, p. 536-570. Disponível em: https://www.cambridge.org/core/services/aop-cambridgecore/content/view/DC9793F05F3F0CA6E58616296A153AF6/S2045381719000200a.pdf/poli tical_insurance_for_the_relative_poor_how_liberal_constitutionalism_could_resist_plutocrac y.pdf. Acesso em: 28 jan.2021.

KANT, Immanuel. Fundamentação da metafísica dos costumes e outros escritos. Trad. Leopoldo Holzbach. São Paulo: Martin Claret, 2004.

LACAN, Jacques. Da psicose paranoica em suas relações com a personalidade seguido de Primeiros escritos sobre a paranoia. 2. ed. Rio de Janeiro: Forense Universitária, 2011.

MALISKA, Marcos Augusto. O Direito à Educação e a Constituição. Porto Alegre: Sergio Antonio Fabris Editor, 2001.

MATTIELLO, Darléa Carine Palma. Educação especial como vetor de inclusão das pessoas com deficiência: insuficiências da política nacional de inclusão. Dissertação (Mestrado). UNOESC, 2016.

NERY DA SILVA, Rogério Luiz. Políticas públicas e administração democrática. Sequência, Florianópolis, n. 64, p. 57-84, jul.2012. Disponível em:

<http://www.scielo.br/scielo.php?pid=S2177-70552012000100004\&script=sci_arttext $>$. Acesso em: 2 out.2021.

NERY DA SILVA, Rogério Luiz; MATTIELLO, Darléa Carine Palma. Direito à cidade e pessoas com deficiência: o bem-estar urbano como vetor para a efetivação de direitos.

Revista de Direito Urbanístico, Cidade e Alteridade, Florianópolis, v. 6, n. 2, p. 01-17, jul/dez. 2020. Disponível em:

https://www.indexlaw.org/index.php/revistaDireitoUrbanistico/article/view/7082/pdf. Acesso em: 2 out.2021.

NUSSBAUM, Martha. Fronteiras da Justiça: deficiência, nacionalidade, pertencimento à espécie. Trad. Susana de Castro. São Paulo: WMF Martins Fontes, 2013. 
ROUDINESCO, Elisabeth. A parte obscura de nós mesmos: uma história dos perversos. Rio de Janeiro: Zahar, 2008.

ROUDINESCO, Elisabeth; PLON, Michael. Dicionário de Psicanálise. Tradução: Vera Ribeiro e Lucy Magalhães. Rio de Janeiro: Jorge Zahar Ed., 1998.

ROUSSEAU, Jean-Jacques. Do contrato social. Trad. Rolando Roque da Silva. Edição eletrônica: Ridendo Castigat Mores, 2001. Disponível em:

http://www.ebooksbrasil.org/adobeebook/contratosocial.pdf. Acesso em: 13.set.2015.

SARLET, Ingo Wolfgang. As Dimensões da Dignidade da Pessoa Humana: construindo uma compreensão jurídico-constitucional necessária e possível. In: SARLET, Ingo Wolfgang (Org). Dimensões da dignidade: ensaios de filosofia do direito e direito constitucional. Porto Alegre: Livraria do Advogado, 2009.

SARLET, Ingo Wolfgang. A eficácia dos direitos fundamentais: uma teoria geral dos direitos fundamentais na perspectiva constitucional. $12^{\mathrm{a}}$ ed. Porto Alegre: Livraria do Advogado, 2015.

SASSAKI, Romeu Kazumi. Inclusão: construindo uma sociedade para todos. $8^{\mathrm{a}}$ ed. Rio de Janeiro: WVA, 2010.

STRAPAZZON, Carlos Luiz; TRAMONTINA, Robison. Justiça e direitos na perspectiva de Martha Nussbaum. In: STRAPAZZON, Carlos Luiz; TRAMONTINA, Robison. Teorias da justiça e teoria da segurança social. Joaçaba: Ed. Unoesc, 2017. p. 31-49.

TROILO, Silvio. I "nuovi” diritti sociali: la parabola dell' integrazione scolastica dei disabili. 2012. Disponível em: https://www.gruppodipisa.it/8-rivista/263-silvio-troilo-i-nuovi-dirittisociali-la-parabola-dell-integrazione-scolastica-dei-disabili. Acesso em: 2 out.2021.

UN - United Nations. Washington Group on Disability Statistics. Disponível em: https://www.washingtongroup-disability.com/. Acesso em: 2 out.2021.

WACHSMANN, Patrick. Libertés publiques. 7ème ed. Paris: Daloz, 2013.

ZANOTTO, Maria Angélica do C. A formação contínua como possibilidade do aprimoramento da ação de problematizar: análise de uma proposta voltada para professores atuantes em Educação Especial. 2002. Tese (Doutorado), Universidade Federal de São Carlos, São Carlos, 2002. 